\title{
Fishing fleet replacement
}

\section{The French policy from 1945 to 1983}

\author{
Eric Meuriot
}

The author describes the French fishing fleet replacement policy from 1945 to 1983 and ascertains from it the objectives and constraints of public policy. While the theoretical and practical negative effects of open-access fisheries were well assessed, the French experience provides an example of the difficulties of carrying out a policy limiting access to fisheries. Domestic conflicts of interest and open competition with foreign countries failed to limit the overall fishing capacity of the French fleet. They have also led the government to focus on shortterm distributional issues rather than on long-term efficiency. It is the author's opinion that similar case studies could be useful for understanding the evolution of the fishing sector as well as for putting into perspective the results of the theoretical literature on open-access fisheries.

Eric Meuriot has a Phd in EconomicsMarine Resources (University of Rhode Island). He is currently resource economist with the IFREMER (Institut Français de Recherche pour l'Exploitation de la Mer), 66 av. d'léna, Paris 75116. France.

The author is indebted to his colieague John Gates on sabbatical leave at IFREM$\mathrm{ER}$ and to an anonymous referee for comments on an earlier version of this paper.

'J. Weber, 'La pêche artisanaie au Sénégal: hypothèses et voies de recherche', Document scientifique CRODT, Dakar, Vol 84, 1980, pp 3-23.
In many countries, the fishing industry presents a similar pattern: structural economic difficulties and a relatively high degree of government involvement. Onc can observe rapid growth of theoretical literature and of more pragmatic literature on the structural difficulties of open-access fisheries and on their remedies. Often there seems little connection between the two. A major question arises then: do governments have a misunderstanding of the specific mechanisms of fisheries or do specific disciplines, including economics, ignore the real constraints in which fisheries policies are formulated? After a brief summary of the main conclusions of economic theory, this article describes the French fishing fleet replacement policy from 1945 to 1983 , and contrasts it with theoretical conclusions. Using this type of description and contrast, an objective analyst can hope to ascertain the objectives and constraints of public policy and to derive some practical conclusions. It is the author's opinion that similar case studies could be useful for understanding the evolution of the fishing sector.

This article begins by describing the European circumstances which prevailed at the beginning of the study period and the clear (and recognized) policy options which existed at that time. It goes on to discuss the evolution of French policy and practice and details the factors which influenced this evolution during the study period. Finally attempts are made to draw some plausible inferences from the experience in France.

\section{The absence of exclusive fishery user rights}

A fundamental characteristic of most fishing activities consists in the absence of exclusive user rights over natural resources. In open-access fisheries, possession of fishing skill, vessels and gear are sufficient for the harvest of natural resources, hence for their share. ${ }^{1}$ In agriculture, and indeed in any well-defined market, ownership or lease of goods and services is a primary condition of exchange. This condition does not exist in an open-access fishery. The resource must first be 'reduced to 
possession', ie captured. Under open-access conditions this capture process can be wasteful of scarce resources.

Since the seminal works of Gordon ${ }^{2}$ and $\mathrm{Scott}^{3}$ in the 1950s, a large number of bioeconomic models have been created to analyse the theoretical economic consequences of open access. Alternative management policies have also been studied using these models. Major results have been to demonstrate the loss in economic efficiency resulting from the absence of an effective resource allocation system limiting access to fisheries. They have shown the practical difference between quotas limiting total catch and the limitation of the number of vessels or of the catch per vessel: the former does not prevent overcapacity of fishing fleets resulting in a loss of economic efficiency. ${ }^{4}$ It is important to note that the methodologies used compared theoretical ideals against an (assumed) zero rent equilibrium. The discrepancy measures a loss in potential economic efficiency. This potential could never be realized in practice unless policy measures were themselves costless and implementation unrestricted by 'other considerations'.

In Europe, some of these conclusions had already been reached by experience. After the first world war, fish stocks in the North Sea were totally replenished. Heavy investments in steam trawlers and the consequent increase in fishing effort led progressively to a decrease in catches per day at sea and in profitability. The catch per unit of effort of British trawlers decreased by more than half between the mid-1920s and mid-1930s for demersal fisheries such as haddock or whiting. ${ }^{5}$ In 1938, $80 \%$ of the French large-scale fishing fleet operating in the North Sea or in other parts of the North-East Atlantic was over 20 years old. This reflected the lack of profitability resulting from the decrease in catches per day and also from the general economic environment (Great Depression).

Twelve European countries concerned by fishing activities in the North-East Atlantic met at the London Overfishing Conference in March 1946. The British government proposed a plan to prevent overfishing and the loss of profitability from fishing operations. Its

${ }^{2} \mathrm{H}$. S. Gordon, 'An economic approach to the optimum utilization of fishery resources', Journal of the Fisheries Research Board of Canada, Vol 10, 1953, pp 442-457; a similar analysis was undertaken in 1911, see P. Andersen, "On rent of fishing grounds": a transiation of Jen's Warming 1911 article with an introduction', History of Political Economy, Vol 15, 1983, pp 391-396.

${ }^{3}$ A. D. Scott, 'The fishery: objective of sole ownership', Journal of Political Economy. Vol 77, 1955, pp 116-124.

${ }^{4} \mathrm{C}$. W. Clark, "Towards a predictive model for the economic regulation of commercial fisheries', Canadian Journal of Fisheries and Aquatic Sciences, Vol 37, 1980, pp 1111-1129.

${ }^{5} \mathrm{D} . \mathrm{S}$. Raitt, 'The rate of mortality of the haddock of the North Sea stock 1919 1938', Rapports el Procés-Verbaux du Conseif International pour l'Exploration de la Mer, CX. Copenhagen, 1939.

${ }^{6} \mathrm{E}$. S. Russel, Overfishing and the remedy', statement submitted on behalf of the British Government Conference Paper No O.F.C.1., Overfishing conference, London, March 1946. analysis was that

if fishing is uncontrolled, the level of stocks will inevitably fall, the catch per unit of effort will diminish progressively and fishing will become unprofitable. ${ }^{h}$

The remedies proposed did not focus on a limitation of total catch:

it seems doubtful whether a quota system could be applied successfully to such an area as, for instance, the North Sea.

Even if the administrative difficulties involved could be surmounted,

it is highly probable that the permitted quota would be reached well bcfore the end of each year, leaving a period in which no fish would be landed (...).

\section{Instead,}

a simpler plan would be to limit directly the number, size and tonnage and/or fishing capacity (e.g. size and number of trawls) of the vessels permitted to fish in a given area. The time seems opportune to consider such a plan, becausc of the reduction in the fishing fleets which has been brought about by the casualties of war.

The European countries faced a choice between two options:

sharing fish resources through limitation of fishing effort; or, 
- open competition or, rather, rivalry between fishing flcets with the risk of reduction in fish stocks and profitability.

In the absence of agreement, the latter option prevailed.

\section{French fleet replacement policy: $1945-83^{7}$}

\section{Open access: Policy declarations versus practice}

Official fleet replacement policy in France since 1945 has been based on a coherent analysis of the conditions for maintaining profitability from fishing activities: it has centred on a balance between fishing capacities, fish stocks and market possibilities. This policy takes into account the already known consequences of open access, and involves the limitation of flect capacities. However, policy has not been translated into practice. The absence of a system for allocating user rights to fish resources is one of the reasons. Such a system could have avoided the effects of rivalry between fleets, both at the European level, for large-scale fisheries, and at national level, for small-scale fisheries.

\section{Government interventions in the post-war period (1945-52)}

By 1945, the French fishing fleet, decimated during the war, had deteriorated. As in other sectors of the economy, government commitment was massive: decisions on vessel construction were dependent on central administration approval; fish prices were controlled and fixed at the administrative level, as was the marketing of fish. The general disorganization of the economy, the low level of supply and high demand justified this involvement. As economic activities recovered, the government operated a progressive disengagement and intervened decisively in the fishing sector:

- Open competition on domestic fish markets was restored. The previous administrative system had indeed many drawbacks: the development of a black market for the high valued species, a decrease in the quality of fish at the retail level, the inadequacy of supply with respect to the regional diversity of demand. However, protection from competition by foreign operators remained in force.

- An interprofessional organization was set up to bring together representatives of small and large-scale ${ }^{8}$ fishing enterprises as well as fish processors. It was given a large measure of economic authority but stayed under government tutelage. It was empowered to determine the number of vessels admitted to operate in different fisheries and to regulate their fishing time.

- Replacement of fishing vessels destroyed in the war became the first priority: 156 large trawlers (60000 GRT) were built between 1946 and 1952 (Figure 1). A specialized bank, Crédit Maritime Mutuel (CMM) existed to distribute low-rate loans for small vessel construction. Due to inflation, its effective financing capacity decreased by $25 \%$ compared to its pre-second world war level. The total French fleet amounted to 220000 GRT, with half for large-scale vessels. The priority for large-scale fishing vessels reflected the decision to participate fully in international competition for the exploitation of fishery resources. This choice was also believed necessary to supply urban centres with food products. 


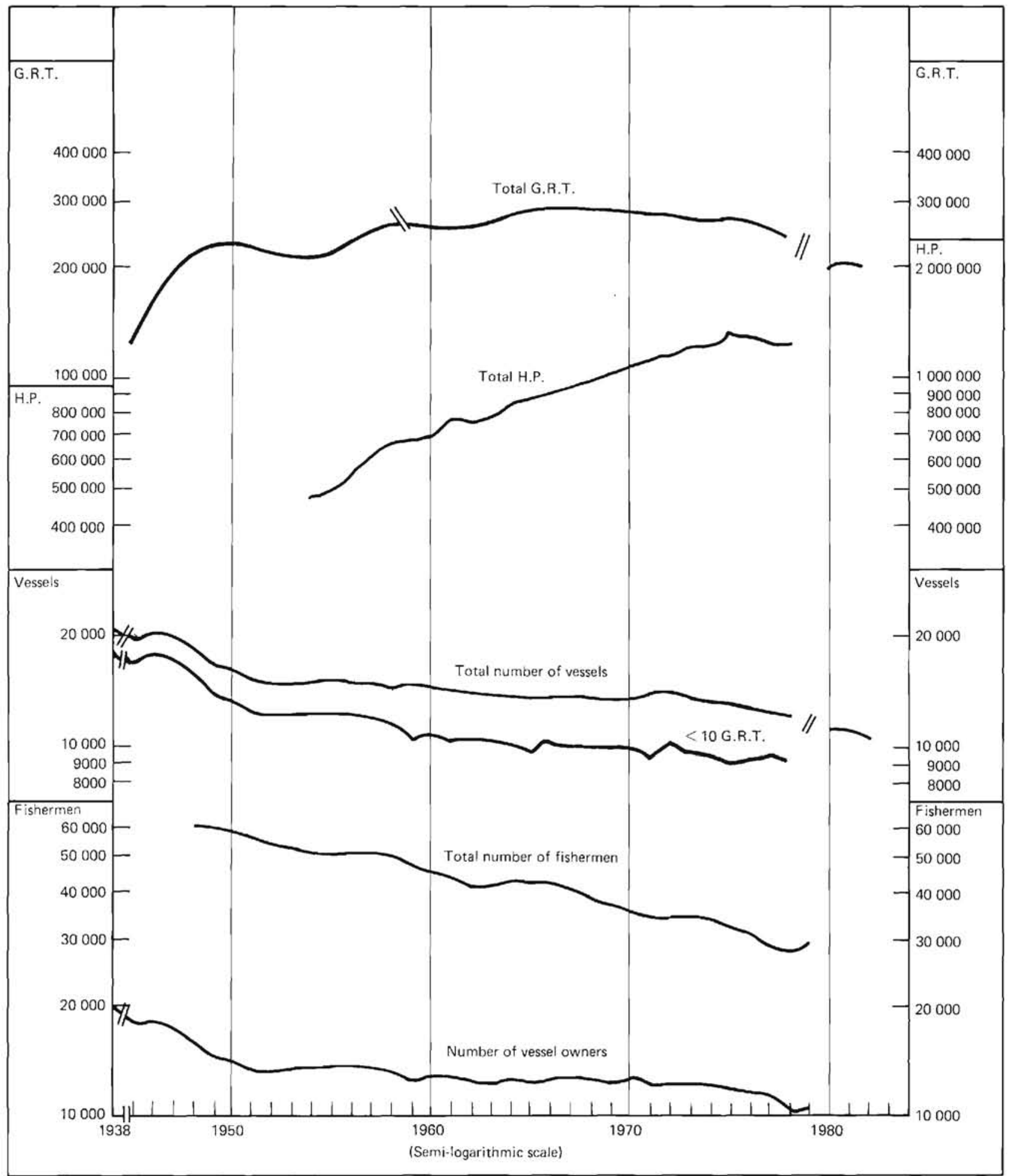

Figure 1. French fishing fleet and fishermen.

This government intervention was decisive. The professional organization set up in 1945 is still extant in 1986. Open competition on domestic markets was maintained and later extended to foreign operators. The initial subsidies for the construction of fishing vessels continued to have major conscquences for many years: the new vessels were able to use 
${ }^{9} \mathrm{OECD}$, 'Subsidies and other financial support to the fishing industries of O.E.C.D. countries', Paris, 1965 and 1971. new technologies (fucl engines instead of steam propulsion); such technologies increased vessel efficiency in a period where stocks were high owing to the interruption of fishing by the war; the profits made and the high resale value of the modern fishing vessels favoured the subsequent purchase of more modern vessels by these enterprises. The discrepancy, alluded to earlier, between policy and practice permitted such technological progress without any parallel requirement for retirement of old vessels.

\section{Fishing expansion (1953-65)}

The rapid recovery, from 1945 to 1948 , was followed by a short period of stability. The trend from 1954 to 1965 was again an increase in fishing capacity and production (Figures 2 and 3 ). The total catch rose from 400000 to 550000 metric tons. This period saw the gradual passage from the elaboration of coherent fleet replacement plans to the abandonment of any attempts to balance fleet capacities, fish stock and market possibilities. The plans were drawn up in the framework of an overall French planning process which was not specific to the fishing sector. It involved both the government and representatives of the profession. The investment plans were merely indicative, and fishing enterprises did not have to comply with them.

The different plans from 1954 to 1965 aimed, on the one hand, to replace $75 \%$ of the 1952 fleet capacity and, on the other hand, to reduce its overall size by $5 \%$ (in GRT) in order to take account of technological progress (Table 1). The logic of such a plan was to keep a balance between fishing capacity and stocks. However, the implementation of these plans ran up against several difficulties, viz international and domestic rivalry for the harvest of fishery resource, and marketing problems.

International rivalry for the appropriation of resources. International competition forced each fishing enterprise to use the most effective techniques and to increase its fishing effort. Subsidies provided by other European governments to their fishing sector accelerated this trend ${ }^{9}$ and were reciprocated in France in order to correct for competitive disparities: for large vessels, the government subsidized the difference between the domestic and foreign construction costs. Under this rivalry, the total GRT of the French fleet increased by $35 \%$.

Rivalry between domestic vessels in coastal zones. The general increase in engine power and the progressive use of synthetic fibres for nets improved the fishing power of vessels. This increased fishing intensity. The government sought in 1955 to reduce domestic competition in coastal zones by limiting access to low rate loans of the CMM only to vessels of more than 18 metres and 50 GRT; limits later increased to 23 metres and 80 GRT. These limits were meant to stop trawling in near-shore coastal zones in order to protect hatcheries and juveniles. These measures were subsequently cancelled owing to the strong hostility of many fishing groups. In exchange, the interprofessional organization was supposed to abolish all exemptions to the general prohibition of trawling within the three-mile limit. Most of these exemptions were in fact maintained and still remain in 1986. The logic of official policy thus ran into strong opposition at the level of interprofessional organizations. 
Fishing fleet replacement

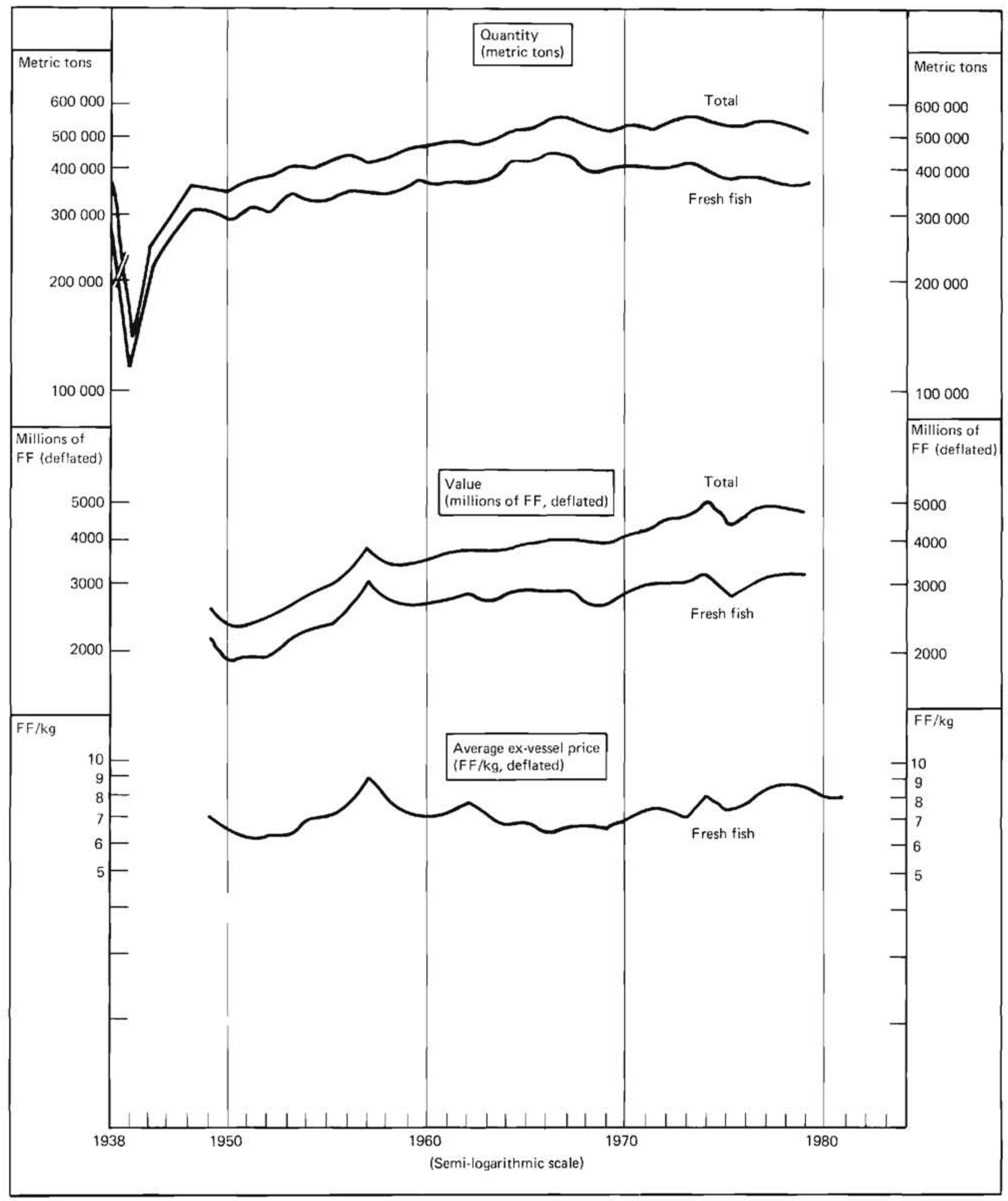

Figure 2. French landings.

Absence of effective action in the processing and marketing sectors. The government department in charge of fisheries limited its action strictly to fishing activities. Processing and marketing of fishery products 


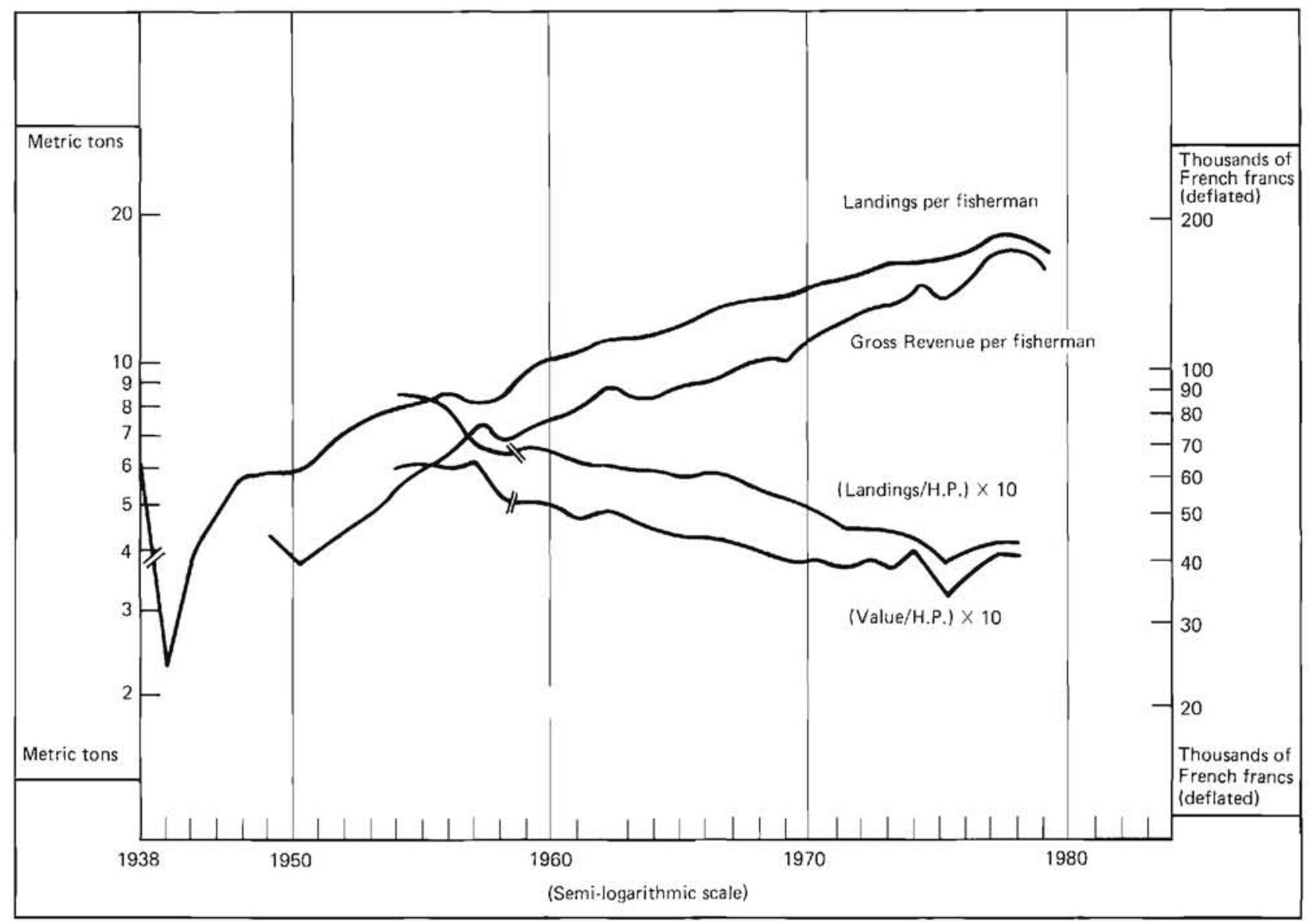

Figure 3. Productivity indicators.

\begin{tabular}{|c|c|c|c|c|c|c|c|}
\hline \multirow{2}{*}{\multicolumn{2}{|c|}{ Planning period }} & \multicolumn{3}{|c|}{$\begin{array}{c}\text { Planned } \\
\text { vessel constructions (unit-GRT) }\end{array}$} & \multirow{2}{*}{$\begin{array}{c}\text { Planned } \\
\text { net } \\
\text { replacement }\end{array}$} & \multirow{2}{*}{$\begin{array}{l}\text { Planned } \\
\text { fleet size } \\
\text { (GRT) }\end{array}$} & \multirow{2}{*}{$\begin{array}{c}\begin{array}{c}\text { Effective fleet } \\
\text { size }\end{array} \\
\text { (GRT-end of period) } \\
210000\end{array}$} \\
\hline & 1953 & Large scale & Small scale & Total & & & \\
\hline \|I & $1954-57$ & 23000 & 30000 & 53000 & -10600 & 199400 & 244000 \\
\hline III & $1957-61$ & 30000 & 20000 & 50000 & 0 & 244000 & 252000 \\
\hline \multirow[t]{2}{*}{ IV } & $1962-65$ & 30000 & 20000 & 50000 & 0 & 252000 & 284000 \\
\hline & $1954-65$ & 83000 & 70000 & 153000 & -10600 & & \\
\hline V & $1966-70$ & 99400 & 28700 & 128100 & +28400 & 312400 & 279000 \\
\hline \multirow[t]{2}{*}{ VI } & $1971-75$ & 70000 & 50000 & 120000 & +8500 & 287500 & 272000 \\
\hline & $1966-75$ & 169400 & 78700 & 248100 & 36900 & & \\
\hline
\end{tabular}

depended on the Department of Agriculture, for which fishery products represented a minor interest.

Until the mid-1960s, the government attempted to limit its intervention in the fishing sector. The increases in aggregate fishing mortalities led to a depletion of several fish stocks. For instance, important stocks such as herring and whiting stocks were biologically overexploited. In the two largest fishing ports, the landings of the major species (herring in Boulogne, whiting in Lorient) fell by half between the mid-1950s and the mid-1960s. For most stocks catch per unit of effort was following a downward trend (Figure 3). At the beginning of the 1960s, the large trawler fishing fleets had to reallocate their fishing effort from these depleted stocks to other underutilized stocks such as saithe and haddock. They also adopted more effective fishing gears: the four seams 
mid-water trawl and the high-opening bottom trawl. The conjunction of large landings of species previously rarely sold, and of the beginning of the European Common Market, implying lower trade barriers within the EEC, produced a sharp decrease in ex-vessel price and in revenues (Figure 2). In the two major French fishing ports, Boulogne and Lorient, the total value of landings fell by about $10 \%$ between 1965 and 1969 while a large part of the fleets had just been replaced (Figure 4). Several strikes took place in the mid-1960s. They led the government to carry out further interventions which remained limited and selective:

- a Regional Fund Market Organization was set up in Boulogne, the largest French fishing harbour. This organization received governmental subsidies to regulate ex-vessel price fluctuations and concerned mainly large vessel activities;

- some experimental operations, such as the testing of new fishing equipment or searching for new fishing grounds, were subsidized.

\section{The logic of international rivalry (1966-75)}

In the mid-1960s French fisheries began a long period of stagnation in production (Figure 2). Total catch remained below 550000 metric tons. Only few fisheries continued to expand: crustaceans and shellfishes in small-scale fisheries; tuna in large-scale fisheries.

The government commitment focused fully on strengthening the competitiveness of large-scale fishing enterprises. In addition to the interventions decided in reaction to different slumps and strikes, other measures were devised to shape the economic structure of large-scale fishing enterprises. As before, the approach was quite logical from a technical, if not economic point of view. Active participation in international competition for the appropriation of fish resources implied the use of the most catch-effective technological innovations. These innovations, such as stern trawling, were costly. It was thereforc necessary to strengthen and increase the investment capacity of the enterprises if France's share of the harvest was to be maintained irrespective of the trends in total catch and CPUE. Hence a policy of encouraging fishing enterprises to merge: fishing enterprises having at least three large-scale vessels were entitled to a subsidy equal to $15 \%$ of the new vessels construction cost and to low rate loans; the required amount of self finance was decreased from 40 to $30 \%$.

This orientation appeared to be the only policy possible, other than abandoning the European and distant fishing grounds and thereby dropping a major part of fishing activitics (amounting to about half of total French landings):

- With the exception of distant tuna fishing, the possibilities of reallocating the fishing effort had become very limited. A sharp improvement in vessel effectiveness, when total fishing intensity increased (Table 2), allowed enterprises to increase their individual share in the total catch; however, the latter decreased. Profitability of enterprises ran the risk of being lower than expected. In addition, after the extension by Iceland in 1959 of its jurisdiction over fishery resources, access to fishing grounds near the shore of foreign countries became uncertain. For these reasons, capital assets were not attracted to the fishing sector.

- The last vessel replacement cycle was very recent; it had taken place in the early 1960s. At that time, most enterprises did not seize the 
Fishing fleet replacement

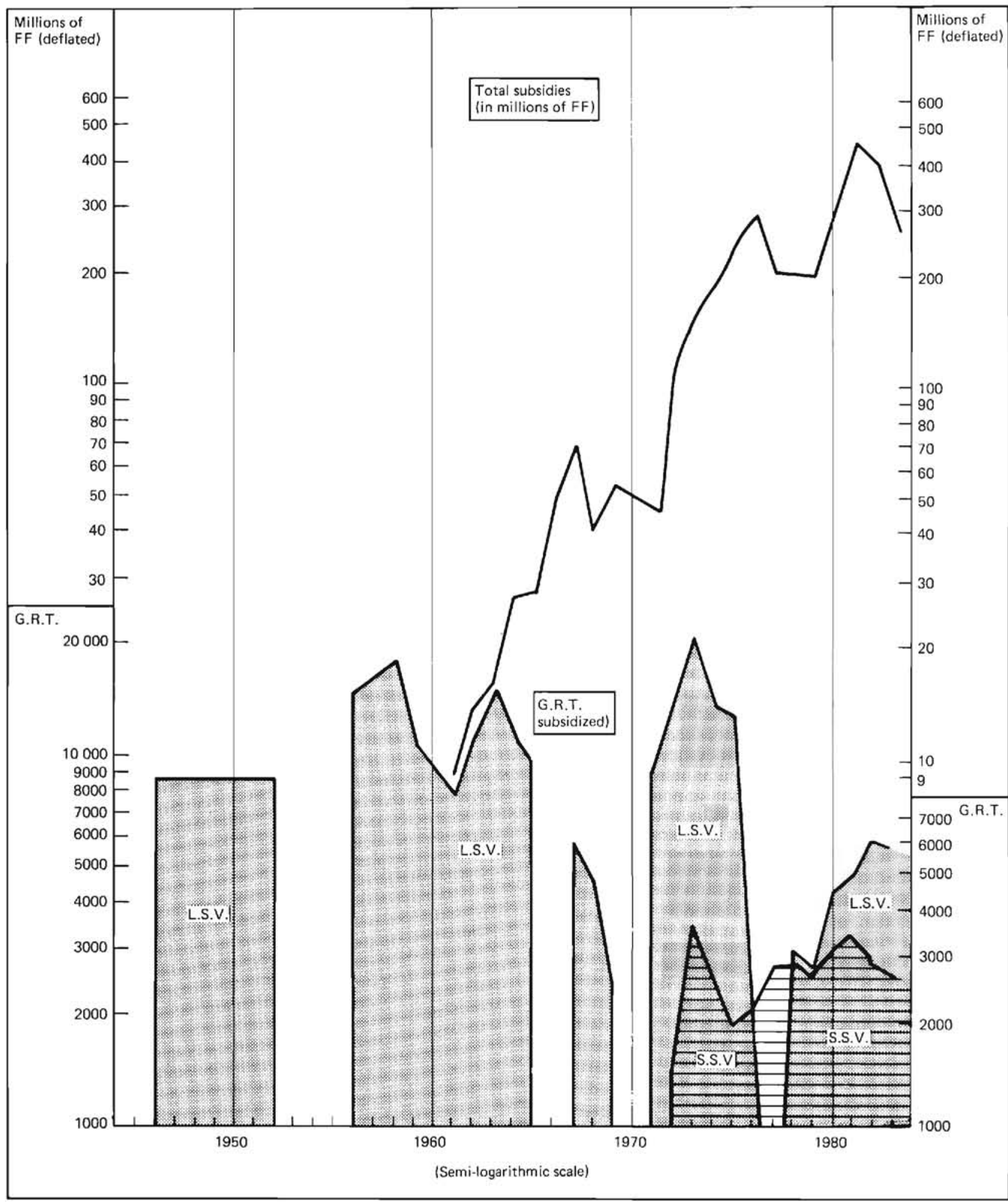

Figure 4. French subsidies to the fishing industry (LSV = large-scale vessels; SSV = small-scale vessels).

opportunity of buying stern trawlers, which are more effective. Their financing capacity was reduced, either because they had recently invested in side trawlers, or because the resale value of these trawlers dropped due to their premature obsolescence. 


\begin{tabular}{|c|c|c|c|c|c|c|c|c|}
\hline & \multicolumn{8}{|c|}{ Table 2: Fishing mortality in the North Sea and west of Scotland (VI) fishing zones } \\
\hline & & ICES & & & Averages & & & \\
\hline & Species & fishing & & & & & & F-MAX \\
\hline & & zones & $1962-65$ & $1967-71$ & $1972-75$ & $1977-81$ & $1982-83$ & \\
\hline & Herring & $\mid V+V I I d$ & 0.45 & 1.07 & 0.94 & 0.22 & 0.23 & \\
\hline & Cod & IV & $0.51^{2}$ & 0.61 & 0.74 & 0.77 & 0.92 & 0.18 \\
\hline & Cod & VI & & 0.54 & 0.66 & 0.78 & 0.76 & 0.31 \\
\hline & Whiting & IV & 0.90 & 0.88 & 0.99 & 0.87 & 0.77 & 0.41 \\
\hline & Whiting & IV & $0.64^{\mathrm{a}}$ & 0.77 & 0.99 & 0.65 & 0.54 & ND \\
\hline & Haddock & VI & & 0.48 & 0.71 & 0.59 & 0.60 & 0.26 \\
\hline Source: ICES. & Haddock & iv & 0.90 & 0.82 & 0.95 & 0.92 & 0.82 & 0.36 \\
\hline${ }^{a} 1963-66$ & Saithe & IV & 0.33 & 0.28 & 0.50 & 0.36 & 0.26 & 0.27 \\
\hline ND F-MAX is not determined (the yield/recruit & Saithe & VI & 0.23 & 0.12 & 0.23 & 0.25 & 0.22 & ND \\
\hline
\end{tabular}

For the period from 1966 to 1975, the professional organization and the government planned a large fleet replacement and increase in tonnage (GRT). In fact, the fleet replacement stayed at a low level until the end of the 1960s (Table 1). Then the increase in ex-vessel prices and in subsidies, as well as the need to adopt stern trawling in order to keep up with foreign fleets and to attract the best crews, led to a rapid and extensive fleet replacement at the beginning of the 1970s (Figure 4). Other European fleets followed the same pattern in terms of fishing capacity either for human consumption or for fish meal. Fishing mortality in the North Sea and in other zones of the North-East Atlantic was at its highest (Table 2). The conjunction of the high level of fishing intensity at the beginning of the $1970 \mathrm{~s}$, of the sharp increase in oil prices and of a temporary slump of ex-vessel prices in 1975, led to a new crisis: most fishing activities were stopped by a general strike. It reflected the weakness to which the fleets most engaged in open competition were reduced, despite their extensive modernization; this was true both for large-scale fishing enterprises and for small ones.

The search for a change in competitive conditions (1975-83)

From the mid-1970s to the beginning of the 1980s, the overall trend in production was a slight decrease. This even affected fisheries such as crustaceans and shellfish which had previously expanded.

A major change in some fisheries occurred with the extension of national jurisdictions over a 200-mile zone. In 1977, the EEC countries extended their jurisdiction in the North-East Atlantic. ${ }^{10}$ The prospect of an effective allocation of the resources, as a substantial change in competitive conditions between countries, became possible. In practice, Eastern European countries' fishing fleets were phased out and the Spanish effort was restrained. A system of catch limitation (TACs and quotas) by species and countries was set up. It concerned mainly large-scale fishing vessels. Competition between EEC fleets for the appropriation of resources was still extant, but was lessened. Up to 1983 , it was more limited by financial difficulties of the fishing enterprises than by an effective sharing of resources. Even supposing that it were fully enforced, the quota system did not in theory prevent competition between vessels from the same fleet: each vessel tried to land the largest part of the quota before it was reached. In practice, when market difficulties appeared, the large-scale fishing organizations adopted short-term adjustments by limiting the landing per vessel.

Up to 1980 , the economic effects of low fish stocks were aggravated by the higher cost of oil and by temporary decreases in ex-vessel prices. This affected mainly trawling activities. In particular, the large-scale fishing enterprises found themselves in financial difficulties. The overall London, 1983. The author traces the European Common Fisheries Policy from the mid-1960s down to the adoption of the new management system (January 1983 package of proposals). 
result was the vulnerability of many fishing enterprises (in Lorient, 17 new vessels, out of a total of 56 , had to be sold), the occurrence of a major strike in 1980, following the 1975 one, and constant governmental involvement in the industry. Low-rate loans and subsidies aimed to enhance new vessel constructions, ex-vessel price stabilization and the coverage of some operating costs. They concerned small-scale vessels as well as large-scale vessels. Subsidies for vessel construction could amount to $25 \%$ of the cost for small-scale vessels and $20 \%$ of the cost for large-scale vessels. The required amount of self-finance was set at $10 \%$ for small-scale vessels and $20 \%$ for large-scale vessels, the remaining source of finance being brought by low-rate loans. The fuel subsidy accounted for about $10 \%$ of the fuel cost. Overall, from 1973 to 1981 , national and EEC subsidies increased by $300 \%$ (Figure 4); in 1981, they amounted to almost $10 \%$ of the value of total French landings. The economic and political context (unemployment, elections) increased the weight of arguments presented by the interprofessional organization in a period where budgetary limitations formed a constraint that only strikes could overcome: the reduction of the trade deficit in fishery products, the maintenance of employment and of 'social peace' became 'convincing' arguments. This was all the more so, since the fishing sector was receiving important subsidies in some other European countries.

At the beginning of the $1980 \mathrm{~s}$, the replenishment of fish stocks exploited by large-scale vessels was rapid (Table 2). It followed the phasing out of Eastern European countries' fleets and the reduction, for lack of profitability, of some fishing capacities of fleets such as the French large-scale fishing fleet. It produced higher catches per vessel, but did not lead to major improvements of operating profits: productivity is only one element of profitability that is associated with the costs of supplies and ex-vessel prices. The former were affected between 1979 and 1983 by the increase in oil prices, caused by the drop of European currencies with regard to the US dollar; the latter have dropped in real terms for the species landed by the large stern trawlers. For the Boulogne large-scale fishing fleet, catch per vessel has increased by $32 \%$ between 1979 and 1983. At the same time, the ex-vessel price decreased in real terms and operating costs rose by $88 \%$. As a result, the average net revenues per vessel became negative from 1980 to 1983.

Since the mid-1970s the possibilities of intervention in the large-scale fishing sector have consisted mainly of preventing the bankruptcy or disappearance of enterprises. Government interest then turned to the replacement of the small-scale fishing fleets (Figure 4). The first stages of delegation of economic autonomy from the central government to regional bodies since 1975 played an important part in the attention given to small-scale fisheries. The increase in regional, national and EEC subsidies was sensitivc. However, the effectiveness of their use was restricted by the difficulty of intervening in a coherent manner in a sector where activities are very dissimilar and often not well known. The many potential recipients of subsidies and the numerous levels of intervention gave rise to the creation of new institutional structures. Only members of small-scale fisheries associations were eligible for subsidies for new vessel constructions. Initially, in the 1970s, these associations were supposed to take a prominent part in the analysis of the orientations to be given to each type of fishing activity, taking into account the level of fish stocks as well as market potentials. Due to their lack of results, Regional Commissions for the Modernization of 
small-scale fishing fleets were set up in 1980 . They were to propose programmes for the replacement of fishing fleets. The functioning of these new structures remained totally administrative. They did not undertake analyses nor propose effective orientations or arbitrations. As an example, from 1980 to 1985 , for Brittany (by far the largest fishing region of France), the Regional Commission made its recommendations on vessel construction subsidies without any study on the evolution of fishing capacity and effort or on the potential impact of the new investments on the stocks, landings and economic results of the existing fleet. Its logic was first to check whether the fishermen asking for a subsidy were entitled to it and then to recommend the approval of subsidies requested on a 'first in - first out basis'. At the beginning of the 1980s, the balancing of fishing capacity, stock levels and fish consumption was still an unrealized objective for small-scale fisheries.

\section{Some lessons drawn from the $1945-83$ period}

\section{The priority given to the large-scale fishing enterprises}

Until the beginning of the 1970s, fleet replacement policy focused mainly on large-scale fishing activities. In parallel, the policy regarding small-scale fisheries was to advocate their evolution toward a smaller number of vessels of larger dimensions. This preference for large-scale fishing resulted from the conjunction of several factors.

An essential economic role. Overall, small-scale fisheries generated greater added value and employment than large-scalc fisheries. The weight of the latter was not preponderant. However, large-scale fleets were essential in that they created at the national level additional wealth that the small-scale fisheries could not technically have generated (the exploitation of the fishing areas in the North Sea or in the West of Scotland required large-scale vessels).

The international rivalry for national shares. Until the 1970 s, the fleet replacement policy followed a precise logic: to increase the effectiveness of fleets in open competition with foreign ones. It implied government intervention, if only to make up for the disparities introduced by subsidies to the fishing sector in other European countries. This policy could not be consistent with the objective of stock management. The immediate problem was to harvest where fish were still in sufficient abundance. To quote Troadec:

For each country, the only strategy that could be considered was to increase its catch capacitics in the hope of increasing its participation more rapidly and more efticiently than that of its rivals. Even in the case of stocks exploited solely by national operators, it was difficult for national operators to impose limits to national expansion in view of the prospects on increasing the national fisheries through expansion of their activities beyond the territorial waters. That is why even in purely national fisheries an indiscriminate expansion strategy was able to prevail; because of competition, any other would have led to a decline of the national share."

The consequences of rivalry between European fleets and of overexploitation were fully appraised by the large-scale fishing enterprises

${ }^{11} \mathrm{~J}$. P. Troadec, 'Introduction to fisheries management: advantages, difficulties and mechanisms', FAO Fisheries Technical Paper, Vol 224, 1983, p 57 and p 20. and the government department in charge of fisheries. This led to the high vulnerability of these enterprises in the 1970s. However, it also led to exploiting other resources that would have been otherwise underutil- 
${ }^{12} \mathrm{M}$. A. Herubel, 'Pêche Maritimes d'Autrefois et d'Aujourd' hui', Bibliotheque des amis de la marine, 1912. ized or harvested only by foreign fleets. Furthermore, the French government was in a better position to negotiate in 1983 with its EEC partners its share of TACs in the North Sea and the West of Scotland fisheries. This allocation of resources remains valid until 1992 and may then be renewed for another ten years.

The lack of knowledge of small-scale fisheries. The importance and structure of small-scale fisheries have never been well known, nor their needs correctly appraised. In the 1960 s, some attempts to set up a development programme for small-scale fisheries showed the practical difficulties of designing an efficient institutional structure able to assess their needs: each year, during four years, the central administration changed the institutional mechanism leading to the selection of pilot projects to be subsidized. In 1976, a survey of small-scale fisheries undertaken by the government stressed the failure to appraise the fundamental characteristics of small-scale fisheries and their needs', as well as the inadequacy of available statistics.

A negative perception of some small-scale fisheries. Small-scale fisheries have been to a large extent associated with towed gears in nearshore waters. As a general rule, these gears have been forbidden in territorial waters (three miles) since 1852 . Numerous exemptions to this rule have been allowed over the years. In addition, the absence of tight enforcement explains the maintenance of such activities until now. These activities have been presented by research bodies as inducing waste by harvesting in hatcheries and catching juveniles. Such allegations are often true, but cannot be generalized. The analyses have been mainly made on the ground of quantities caught but not on the criteria of added value or profit. In the absence of such criteria, the prevailing analyses could only enjoin the disappearance of towed gears in nearshore waters and the development of large-scale fishing: this was a policy advocated in $1912^{12}$ and which has been given the force of a dogma.

The effectiveness of the professional organization. The engagement in international competition and the difficulties in appraising small-scale fisheries needs or prospects have played a part in increasing the influence of the large-scale fishing enterprises organization. Either through the channel of the institutional structures set up in the fishing sector or by direct intervention, their representatives have developed close links with the government department in charge of fisheries. An example of the effectiveness of the large-scale fishing organization is given by the vessel construction plans for the period from 1966 to 1975 : more than two thirds of the replacements concerned large vessels while their fleet amounted to only half of the total French tonnage (GRT); with the planned constructions and the subsidies, the French large-scale fishing fleet would have been totally replaced in ten years.

The weight of economic doctrines. Major decisions affecting the prospects of the fishing sector have often been due to more general economic politics. They cannot be understood without referring to the prevailing economic doctrines. For instance, the measures taken in the $1960 \mathrm{~s}$ in order to induce a concentration of large-scale fishing enterprises were not specific to the fishing sector. They combined with a more general policy consisting in achieving a more competitive economy by the concentration of enterprises. The growth and modernization of 
the French economy may have led to an implicit 'big is better' postulate in fisheries as in other economic sectors. When applied to fisheries, the future of fishing activities, under this postulate, relied more on large-scale fishing vessels and enterprises than on small vessels with lesser capital requirements. In the mid-1970s, the economic environment changed drastically and the prevailing doctrines were modified. The priority also shifted from the large-scale fisheries to small-scale ones. Vote-catching decisions may also have grown in importancc.

\section{Some limits to 'rational' management}

A policy of 'rational' management of fish resources emerged in France in the 1970s. The return to a search for a balancc between fleet size, fishing effort, stock levels and market potentials took place in a very different context than in the 1950s or 1960s. The extension of national jurisdiction over a 200-mile exclusive economic zone led to the consideration of national or EEC control of the exploitation pattern of fish resources. However the possibility of reaching at the European and at the national levels an agreement as to what represents a 'rational' balance between fleet capacity and stock levels is open to doubt.

The terms 'rational' or 'optimal' encompass very diverse meanings. These range from the maximization of the sustainable yield (the ' $F$ max' invented by biologists), to the maximization of total profits or of added value. In other instances, instead of referring to theoretical models, whether they are biological or economic models, the term 'rational' reflects the search for a 'status quo': the maintenance of fishing capacities at their current levels, and the maintenance of employment.

Without taking into account the nature of the real objectives pursued by the governments or by the different professional lobbies, the definition of practical actions needed to reach a 'rational' or 'optimal' management remains very uncertain: the available information is often poor and inadequate. In the 1970s, different administrative and research reports stressed the deficiencies of the national statistical system, especially when it dealt with small-scale fisheries. This leads to two remarks:

- The participation of French fleets in international competition and the weight of the international problems that have been induced explain the minor effort devoted to the biological study of fish stocks exploited by small-scale vessels.

- The methods used to forecast or plan the replacement of small-scale fishing fleets remain rudimentary. With few exceptions, they are based on a static analysis of the age composition of the fishermen and the fleets, and on imprecise evaluations of stock levels, the latter still being little known. Recommendations are usually made to prevent an increase in fishing intensity; however, it has not been determined which type of fleet replacement leads to an increase in fishing intensity. The weakness of the practical analyses undertaken explains in part the inadequacy of the statistical system. The latter has not been developed with a goal of fisheries management but with an administrative goal of fishermen and vessel census.

The gap between a declared search for 'rational' or 'optimal' programmes of fishing fleet replacement, and actual practice is wide. The absence of political choices aiming at the design of a resource allocation system limiting access is one of the reasons. This gap may also result 
from the fact that the terms 'rational' or 'optimal' take for granted well-determined valuation criteria as well as the possibility of making a choice between different objectives. As soon as objectives are precisely stated, divergences of intercsts between groups or countries emerge. The last 40 years show that a large number of important decisions taken in the fishing sector do not result from a classification of well-defined objectives. They come either from political choices totally outside the fishing sector (eg creation of the EEC, budgetary policies) or from the outcome of a series of crises whose solution has very often been based on the acceptance of propositions prepared by some well-organized constituent of the profession. On the contrary, as an example, numerous attempts to eliminate trawling in nearshore waters (within 3 miles) have broken down; they had nevertheless been presented by the government or by research institutes as being absolutely necessary for a 'rational' exploitation of fish resources.

\section{Conclusion}

This survey of French fishing fleet replacement policy since 1945, of its objectives and results, leads to four main conclusions:

- Technology coupled with international rivalry occupy a key role in fisheries: its use still determines to a large extent the possibility of appropriation and share of fish resources in such a manner that what is usually called technical 'progress' may result in an increase in production costs and a decrease in total benefits; it unavoidably creates a modification of the distribution of benefits.

- The declarations made in the 1970 s on the need for a 'rational' fleet replacement policy echoes those already made 30 to 40 years before. The adjunction of the term 'rational' alters the appraisal of reality to the extent it assumes that choices can be based on an 'objective' analysis of a given situation. On the one hand, rational criteria are not identical for each individual or group, their objectives and constraints being often different, if not opposite. On the other hand, the fishing sector is part of an economic and political system from which emerge other constraints and objectives which can dominate decisions. These two aspects are quite common ${ }^{13}$ but are left out of the scope of the traditional literature on fisheries economics and management.

- The dichotomy made in the economic literature between efficiency and equity appears somehow artificial. Public actions made in order to improve the overall efficiency of the fishing industry have failed because their distributional implications had not been fully assessed. To quote Bromley and Bishop:

Any public action is, above all else, the restructuring of individual and group opportunity sets; the shifting among economic units of relative and absolute advantage. The singular issue in all public choice economics is efficiency for whom? ${ }^{14}$

${ }^{13}$ See, for example, L. and B. Chatterton, 'How much political compromise can fisheries management stand?' Marine Policy, Vol 5, No 2, 1981, pp 115-134. ${ }^{14} \mathrm{D}$. W. Bromley and R. C. Bishop, 'From economic theory to fisheries policy: conceptual problems and management prescriptions', in Lee Anderson, ed, Economic Impact of Extended Fisheries Juridiction, Ann Arbor Science, 1977, pp 281-307.

This issue appears to be the major one in the case of the French and EEC fisheries policy.

- The search for a balance between fleet replacement, stock levels and market possibilities remains mainly a theoretical policy. In practice, it has resulted for small-scale fisheries in a multiplication of institutional structures and of government intervention, the 
effectiveness of which may come up against the absense of resource allocation systems limiting access, but also against the lack of adequate statistical, technical and scientific support. Basic information on fleet capacity and the effect of fishing effort on stock levels and catch are still often missing.

A review of the evolution of the fishing sector must go beyond the mere analysis of technical and market forecast or of bio-economic model results. It requires a study of the relationships between the different economic agents and institutions involved in the fishing sector, of their organization and methods of intervention, of their projects and strategies. It requires also an analysis of the impact that the economic system and political doctrines may have on the fishing sector. This involves a multidisciplinary research effort. Bio-economic models have provided fundamental results such as the mechanism of rent dissipation in open-access fisheries or the theoretical interest of alternative resource allocation measures. However, the scope of this type of economic analysis is too limited to lead to alternative management measures consistent with the economic and political structures prevailing in a specific country or region. 


\section{Update}

\section{A further note to making sense of the dollars: income distribution among Atlantic Canadian fishermen and public policy}

This note updates a previous article on socio-economic survey data of Atlantic Canadian fishermen. It completes the previous analysis by presenting data on total enterprise costs and net fishing incomes.

Our earlier essay of the same title presented the results of a preliminary reanalysis of the socio-economic survey data on fishermen and their households gathered by the recent Canadian Task Force on Atlantic Fisheries (TFAF).' We argued that a complete understanding of the factors affecting income distribution among fishermen required an analysis which accounts for the impact of social organizational dimensions such as the sector within which men fish (inshore offshore), enterprise ownership (owner/non-owner) and crew position (captain/crewman). Our analysis of the TFAF data demonstrated that these variables exerted a marked influence on the distribution of income. In particular, participants in the offshore sector were shown to generate much higher incomes than their inshore counterparts. Moreover, our examination of gross incomes revealed that, within each sector, those who owned and/or captained an enterprise realized much higher incomes than those who did not. In addition, owning and non-owning captains in the offshore sector were shown to be the 'high-line' gross income earners within the Atlantic Canadian industry. We argued that these findings are more demonstrative of the actual conditions of the industry than those presented by the TFAF. ${ }^{2}$ While agreeing with the TFAF contention that povertylevel incomes are experienced by many in the industry, our analysis suggests that this condition is associated largely with inshore fishermen. Finally, we outlined several policy implications that arise from our analy- gross income. A measure of relative efficiency within the various segments of the industry can be obtained by forming the ratio of costs to gross income. As in our first analysis, we will focus our attention on the influence of three organizational dimensions: sector participation, enterprise ownership and crew position. ${ }^{3}$ This is followed by a brief discussion of several additional implications of our analyses for the relation between income distribution and public policy in the fisheries.

sis concerning steps that could be taken to ensure a more equitable distribution of income.

Our purpose here is to complete the analysis by presenting the data on total enterprise costs and net fishing incomes. We will also address the question of the relationship of costs to

\section{The distribution of expenses ${ }^{4}$}

Figure 1 profiles the distribution of average total expenses in relation to sector participation, enterprise ownership and crew position. ${ }^{5}$ These data show that each of the three organizational dimensions has a marked influence on enterprise costs. First, the

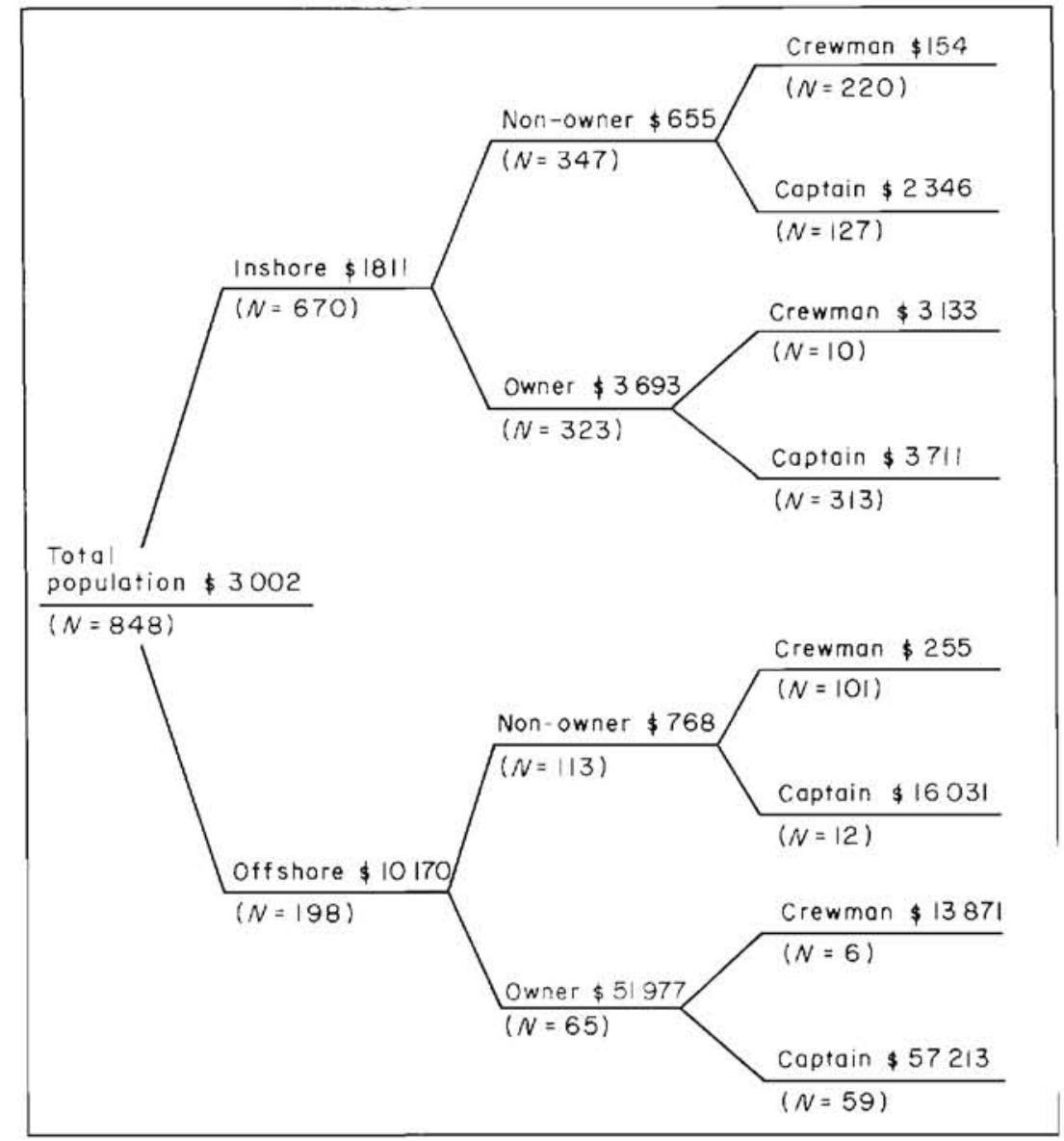

Figure 1. Distribution of average total expenses by sector participation (inshore/offshore), enterprise ownership (owner/non-owner) and crew position (captain/crewman). 